\title{
A FINITE ELEMENT FOR ACTIVE COMPOSITE PLATES WITH PIEZOELEC- TRIC LAYERS AND EXPERIMENTAL VALIDATION
}

\author{
M. Sartorato ${ }^{1}$, R. de Medeiros ${ }^{1}$, V. Tita $^{1}$ \\ ${ }^{1}$ Department of Aeronautical Engineering, Aeronautical Structures Group, São Carlos School \\ of Engineering at the University of São Paulo (murilosart@gmail.com)
}

\begin{abstract}
The study of smart materials for uses in the aerospace, aeronautics and petroleum industries has increased due to the potential of such materials for several applications such as structure health monitoring, damage identification, vibration control and/or suppression, energy harvesting, along with others. In particular, piezoelectric smart composite laminateslaminates made of fiber reinforced polymers in which some or all of the layers contain piezoelectric fibers - are widely studied for being able to serve as both actuators and sensors in the cited applications and having mechanical properties with the capacity to attend the high requirement of the mentioned areas. One of the main obstacles to the practical application of this technology is the difficulty in the prediction and simulation of the behavior of such structures. In this work, a model for structural composite laminates containing active piezoelectric layers is presented and used to formulate a degenerated shell quadratic finite element with eight nodes. The element was implemented into a Python routine and numerical results were compared to the finite element commercial package Abaqus Experimental results of an aluminum plate with piezoelectric patches attached are presented as well. The numerical results, using the formulation implemented by the element, were compared to the experimental analyses and to a full-scale model in which the full laminate, including the fibers, was modeled using Abaqus' solid elements, both structural and piezoelectric.
\end{abstract}

Keywords: finite elements, piezoelectric composites, active structure.

\section{1. INTRODUCTION}

In recent years, the study, research and usage of smart structures material in both academic and industrial environments has greatly increased. Particularly, in the aeronautic, petroleum and spatial industries, the study of piezoelectric materials as embedded sensors and actuators in smart structures has received great attention due to their focus on highly optimized structures and the large scale of applications this kind of materials have such as damage identification, structure health monitoring, vibration control and suppression, flow control and energy harvesting. 
The development of piezoelectric materials in the form of thin fibers in the last years, improved even further the possibilities of piezoelectric smart structures. The more common used piezoelectric ceramics introduces some limitations in both production of embedded sensors and actuators due to its inherent brittleness, thickness, and low flexibility. The concept of piezoelectric fibers gave rise to the creation of laminated materials fashioned from layers of active fibers embedded in polymer matrixes, resulting in smart composite materials with smaller thickness and high flexibility, which can be easily attached to curved surfaces.

In particular, this last characteristic of piezoelectric smart composites having high flexibility and being able to adjust itself to curved surfaces lead to easier applications in some key structural elements in the petroleum, aeronautic and spatial areas, such as pipelines, airplane and satellite fuselages and wing-skins. However, several obstacles remain to the practical application of this technology such as challenging and costly manufacturing; difficult prediction and obtainment of both mechanical and electrical properties; and a not fully understood mechanical behavior and few commercial simulation packages that leads to hard to simulate structures.

Numerous works have been published in the last years about how to correct simulate the mechanical behavior of such structures using finite elements and, therefore, several models already exist for the correct modeling of piezoelectric materials integrated with smart structures. However, the majority of them are modeled for the more common piezoceramics, using solid elements, which are not computationally efficient or appropriate for the use in larger scale models or thin structures. Also, some researchers [10] defend that simpler models cannot completely simulate a smart composite, and simulations must be made using a microscale modeling of each fiber.

These approaches come with a great computational cost and are impractical for large structures. As such, several researchers implement plate finite element models that simulate smart composites; in particular, some researchers [5-6, 11] presented linear plate finite element models for active composites with increasing complexity theories, yet few offer comparisons of the bi-dimensional models to already implemented ones.

The focus of this paper is the modeling and implementation of a degenerated shell finite element for use with smart piezoelectric laminate composites materials, which can be used in curved surfaces based on works found in the literature. The element was implemented into a Python subroutine and compared to the finite element commercial package Abaqus. The results were also compared to experiments made by Medeiros [7] that were used to validate the proposed model.

\section{FORMULATION OF THE ELEMENT}

In this section the assumptions, mathematical model and characteristics of the implemented element are presented and briefly discussed. The geometric model, kinematic assumptions, constitutive equations for a piezoelectric active layer of composites, the composite layer-up equations, and the electrical assumptions used are presented. The element is modeled based on the degenerated shell element presented by literature [1], extending it for laminated 
orthotropic materials using the work of Ochoa and Reddy [9]. The constitutive equations for a piezoelectric active layer were based upon the work of Paik et al. [11] and D., Köppe and Gabbert [5]. Electrical assumptions were made based on the work of Marinkovic et al. [6] and are discussed below.

\subsection{Degenerated shell element, kinematic assumptions and strains calculation}

Degenerated shell elements are bi-dimensional finite elements that through the use of three distinct coordinates systems and the use of the Reissner-Mindlin thick plate kinematic assumptions - the stress component perpendicular to the mid-surface is neglectable and any line in the thickness direction of a shell remains straight after deformation, but not necessarily normal to the mid-surface [13] - to simulate curved shells. The resulting element is not based on classic shell theories, and through the use of virtual stiffness for the drilling degree of freedom and reduced integration, can be used in both thin and thick curved shells.

The classic kinematic equations for the displacements of a curved plate can be written using by using three different coordinate systems, shown in Figure 1: the isoparametric or natural system $\left(\xi_{1}, \xi_{2}, \xi_{3}\right)$, whose variables take values between -1 and +1 and is where the shape functions are defined; the global system $\left(x_{1}, x_{2}, x_{3}\right)$, a Cartesian, fixed system where the structure behavior is described; and the local or co-rotational system $\left(x_{1}^{\prime}, x_{2}^{\prime}, x_{3}^{\prime}\right)$. The corotational system varies from node to node where, the $x_{1}^{\prime}$ and $x_{2}^{\prime}$ axis are given by the normalized vectors that defines the tangent plane of the plate's mid-surface in a given node, and the $x_{3}^{\prime}$ axis is the normalized normal vector to this plane.

The mechanical modeling of the element was chosen as a degenerated shell because of the use of a co-rotational system of coordinates. The local system rotates with the element as a discretized curved surface revolves over the global Cartesian system. This is an interesting property for modeling both laminated and piezoelectric materials as their constitutive equations are written and integrated through the thickness direction, which is greatly facilitated in the local system as it is given by the $x_{3}^{\prime}$ axis without any need for coordinate transformations.
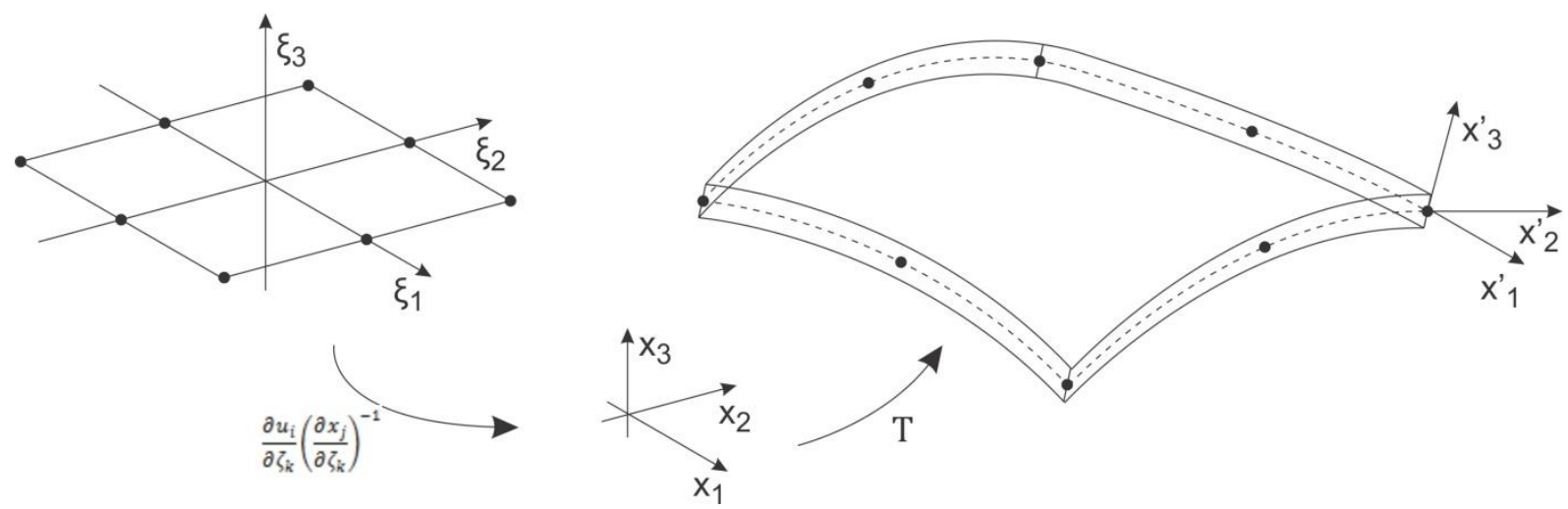

Figure 1. Coordinates systems and transformations used in a degenerated shell element

Using this different systems, the coordinates of a given point of the shell $\left(x_{1}, x_{2} x_{3}\right)$, in a element discretized by the quadratic Hermitian shape functions $\phi_{i}\left(\xi_{1} \xi_{2}\right)$ [2] are given by a 
sum of the Cartesian coordinates of the mid-surface and the thickness of the shell using the vector $T_{3 i}$, as shown by Eq. 1 . The vector $T_{3 i}$ is the tangent normalized vector of the midsurface of the shell at a given point and is part of the coordinate transformation matrix from the local system to the global system, defined by Eq. 2 .

$$
\begin{aligned}
& \left\{\begin{array}{l}
\mathrm{x}_{1} \\
\mathrm{x}_{2} \\
\mathrm{x}_{3}
\end{array}\right\}=\sum_{\mathrm{i}=1}^{8} \phi_{\mathrm{k}}\left(\left\{\begin{array}{l}
\mathrm{x}_{1}^{\mathrm{k}} \\
\mathrm{x}_{2}^{\mathrm{k}} \\
\mathrm{x}_{3}^{\mathrm{k}}
\end{array}\right\}_{\text {mid }}+\zeta_{3} \frac{\mathrm{h}_{\mathrm{i}}}{2} \mathrm{~T}_{3 \mathrm{i}}\right) \\
& \mathrm{T}_{\mathrm{i}}^{\mathrm{n}}=\left\{\begin{array}{l}
\mathrm{e}_{1}^{\prime} \\
\mathrm{e}_{2}^{\prime} \\
\mathrm{e}_{3}^{\prime}
\end{array}\right\}=\left[\begin{array}{ccc}
\mathrm{x}_{1, \xi_{1}}^{\mathrm{n}} & \mathrm{x}_{2, \xi_{1}}^{\mathrm{n}} & \mathrm{x}_{3, \xi_{1}}^{\mathrm{n}} \\
\mathrm{x}_{1, \xi_{1}}^{\mathrm{n}} & \mathrm{x}_{2, \xi_{2}}^{\mathrm{n}} & \mathrm{x}_{3, \xi_{3}}^{\mathrm{n}} \\
& \mathrm{e}_{1}^{\prime} \times \mathrm{e}_{2}^{\prime}
\end{array}\right], \mathrm{H}^{\mathrm{n}}=\left\{\begin{array}{c}
-\mathrm{T}_{\mathrm{i}_{2}} \\
\mathrm{~T}_{\mathrm{i}_{1}}
\end{array}\right\}, \mathrm{T}_{\mathrm{R}}^{\mathrm{n}}=\left\{\begin{array}{c}
\mathrm{T}_{\mathrm{i}_{1}} \\
\mathrm{~T}_{\mathrm{i}_{2}}
\end{array}\right\}
\end{aligned}
$$

As such, in the co-rotational system, the displacement of any point can be given by a sum of the displacements at the mid-surface $\left(u_{1}^{\prime 0}, u_{2}^{\prime 0}, u_{3}^{\prime 0}\right)$ and a linear function on the rotations about the $x_{1}^{\prime}$ and $x_{2}^{\prime}$ axis $\left(\theta_{1}^{\prime}, \theta_{2}^{\prime}\right)$. In a discretized form, the same equation can be written using the degenerated coordinate transformation matrix $H$.

$$
\mathrm{u}^{\prime}=\left\{\begin{array}{l}
\mathrm{u}_{1}^{\prime} \\
\mathrm{u}_{2}^{\prime} \\
\mathrm{u}_{3}^{\prime}
\end{array}\right\}=\left\{\begin{array}{l}
\mathrm{u}_{1}^{0^{\prime}} \\
\mathrm{u}_{2}^{0^{\prime}} \\
\mathrm{u}_{3}^{0^{\prime}}
\end{array}\right\}+\mathrm{x}_{3}^{\prime}\left\{\begin{array}{l}
\theta_{1}^{\prime} \\
\theta_{2}^{\prime}
\end{array}\right\}=\sum_{\mathrm{i}=0}^{\mathrm{n}} \phi_{\mathrm{i}}\left(\xi_{1}, \xi_{2}\right)\left\{\begin{array}{l}
\mathrm{u}_{1}^{0^{\prime}} \\
\mathrm{u}_{2}^{0^{\prime}} \\
\mathrm{u}_{3}^{0^{\prime}}
\end{array}\right\}+\zeta_{3}\left(\frac{\mathrm{h}_{\mathrm{i}}}{2}\right) \phi_{\mathrm{i}}\left(\xi_{1}, \xi_{2}\right) \mathrm{H}_{\mathrm{i}}\left\{\begin{array}{l}
\theta_{1}^{\prime} \\
\theta_{2}^{\prime}
\end{array}\right\}
$$

As Eq. 3 shows, this element needs five degrees of freedom to complete describe $\left(u_{1}^{\prime 0}, u_{2}^{\prime 0}, u_{3}^{\prime 0}, \theta_{1}^{\prime 0}, \theta_{2}^{\prime 0}\right)$ the structure. A coordinate transformation using the coordinate transformation matrixes $T$ and its degenerated counterparts for the rotations degree of freedom $H$ and $T_{R}$, can be applied to recover the six global degrees of freedom $\left(u_{1}^{0}, u_{2}^{0}, u_{3}^{0}, \theta_{1}, \theta_{2}, \theta_{3}\right)$, shown in Eq. 4.

$$
\mathrm{u}=\sum_{\mathrm{i}=0}^{\mathrm{n}} \phi_{\mathrm{i}}\left(\zeta_{1}, \zeta_{2}\right) \mathrm{T}_{\mathrm{i}}^{\mathrm{T}}\left\{\begin{array}{l}
\mathrm{u}_{1 \mathrm{i}}^{0} \\
\mathrm{u}_{2 \mathrm{i}}^{0} \\
\mathrm{u}_{3_{\mathrm{i}}}
\end{array}\right\}+\zeta_{3}\left(\frac{\mathrm{h}_{\mathrm{i}}}{2}\right) \phi_{\mathrm{i}}\left(\xi_{1}, \xi_{2}\right) \mathrm{H}_{\mathrm{i}} \mathrm{T}_{\mathrm{R}_{\mathrm{i}}^{\mathrm{T}}}^{\mathrm{T}}\left\{\begin{array}{l}
\theta_{1} \\
\theta_{2} \\
\theta_{3}
\end{array}\right\}
$$

The constitutive equations for composites are based in the co-rotational system of coordinates. As such the strain fields need to be calculated in the co-rotational system and are dependent on the displacement gradients. These gradients can be calculated in the global system of coordinates and transformed using the T matrix, as shown in Eq. 5.

$$
\frac{\partial \mathrm{u}_{\mathrm{i}}^{\prime}}{\partial \mathrm{x}_{\mathrm{j}}^{\prime}}=\mathrm{T}_{\mathrm{ki}} \frac{\partial \mathrm{u}_{\mathrm{k}}}{\partial \mathrm{x}_{\mathrm{l}}} \mathrm{T}_{\mathrm{lj}}, \frac{\partial \mathrm{u}_{\mathrm{i}}}{\partial \mathrm{x}_{\mathrm{j}}}=\frac{\partial \mathrm{u}_{\mathrm{i}}}{\partial \zeta_{\mathrm{k}}}\left(\frac{\partial \mathrm{x}_{\mathrm{j}}}{\partial \zeta_{\mathrm{k}}}\right)^{-1}=\frac{\partial \phi_{\mathrm{m}}}{\partial \zeta_{\mathrm{k}}}\left(\frac{\partial \phi_{\mathrm{n}}}{\partial \zeta_{\mathrm{k}}}\right)^{-1} \mathrm{x}_{\mathrm{j}}^{\mathrm{n}} \mathrm{u}_{\mathrm{i}}^{\mathrm{m}}
$$

Using the premise of a linear system with small strains and displacements, the symmetry property of the strains, the strain can be given by the vector in Eq. 6. As the ReissnerMindlin kinematic assumptions, $\sigma_{33}^{\prime}=0$, using the orthotropic constitutive equation in Eq. 9, $\varepsilon_{33}^{\prime}=0$. Using a classical approach of a displacement based element, the strain fields can be summarized by the degrees of freedom using the following matrixes in Eq. 6 . 


$$
\varepsilon^{\prime}=\left\{\begin{array}{c}
u_{1,1}^{\prime} \\
u_{2,2}^{\prime} \\
u_{1,2}^{\prime}+u_{2,1}^{\prime} \\
u_{2,3}^{\prime}+u_{3,2}^{\prime} \\
u_{1,3}^{\prime}+u_{3,1}^{\prime}
\end{array}\right\}=\left[\begin{array}{cc}
B_{m} & \xi_{3} B_{f} \\
B_{s_{0}} & B_{s_{1}}+\xi_{3} B_{S_{f}}
\end{array}\right]^{n}\left\{\begin{array}{l}
u_{i} \\
\theta_{i}
\end{array}\right\}^{n}=\left\{\begin{array}{l}
\varepsilon \\
\gamma
\end{array}\right\}=\left\{\begin{array}{c}
\varepsilon_{0} \\
\gamma_{0}+\gamma_{1}
\end{array}\right\}+\xi_{3}\left\{\begin{array}{c}
\kappa_{f} \\
\kappa_{t}
\end{array}\right\}
$$

Equation 6 also shows that the common used assumption for laminate composite plates that the in plane strains can be separated in a membrane contribution $\left(\varepsilon_{0}\right)$ and a flexural contribution, linearly proportional to the curvature of the plate $\left(\kappa_{f}\right)$ naturally arise. The same condition arises for the transversal distortions that can be decomposed into three terms: a shearing portion $\left(\gamma_{0}\right)$, related to the mid-surface displacements, and a torcional portion $\left(\gamma_{1}\right.$ and $\kappa_{t}$ ) related to the rotations both directly $\left(\gamma_{1}\right)$ and linearly $\left(\kappa_{t}\right)$. This kind of decomposition is not common as proved by literature [9], generally, these terms are not significant to the solution of the problem. In this model this decomposition will be used as part of the piezoelectric effect are due to transversal shear stresses, which can be influenced by these terms.

Also, for a simpler formulation of the finite element, the $B_{u}, B_{u \phi}$ and $H_{u}$ matrixes can be defined:

$$
B_{u}=\left[\begin{array}{cc}
B_{m} & 0 \\
0 & B_{f} \\
B_{s_{0}} & B_{s_{1}} \\
0 & B_{s_{f}}
\end{array}\right]^{n}, B_{u \varphi}=\left[\begin{array}{cc}
B_{m} & 0 \\
0 & B_{f}
\end{array}\right]^{n}, H_{u}=\phi_{n}\left[\begin{array}{cccc}
1 & 0 & 0 & \\
0 & 1 & 0 & T^{n} \\
0 & 0 & 1 &
\end{array}\right]^{n}
$$

\subsection{Smart composites constitutive equations}

Problems with piezoelectric materials are problems with a mechanical-electrical coupling in which an electric potential gradient causes deformation and vice-versa. There are four different ways of writing the mechanical-electrical coupling constitutive equations based on permutations of the stress, strain, electrical field and displacement tensors as dependable or undependable variables [4]. For most problems finite element problems, in general the e-form is the most interesting which leaves the strains and electrical fields as independable variables. In this form, the mechanic-electrical coupling is characterized by the $e_{k i j}$ piezoelectric coefficients, and can be summarized by the tensorial relation in Eq. 8:

$$
\begin{gathered}
\sigma_{i j}=C_{i j k l}^{E} \varepsilon_{k l}-e_{k i j} E_{k} \\
D_{i}=e_{i k l} \varepsilon_{k l}+d_{i k}^{\varepsilon} E_{k}
\end{gathered}, i, j, k, l=1 . .3
$$

where: $\sigma_{i j}, \varepsilon_{k l}$ and $E_{k}$ are respectively: the stress, strain, and electrical fields; $D_{i}$ are the components of the electrical displacements (or electrical fluxes); $C_{i j k l}^{E}$ is the fourth order elastic tensor for the short-circuit electrical bounding conditions ( $\mathrm{E}=$ constant); $d_{i k}^{\varepsilon}$ is the dielectric constants for uniformly displaced mechanical boundaries ( $\varepsilon=$ constant); and $e_{i k l}$ are the piezoelectric coupling coefficients. 
Due to the symmetry of $\mathrm{C}$, e and $\mathrm{d}$; the consideration that piezoelectric layers are transversely isotropic; using the assumption that $\sigma_{33}=0$; and uniaxial transversal polarization over the piezoelectric layers $\left(E_{1}=E_{2}=0\right)$ hypothesis, we obtain the constitutive equation for a orthotropic piezoelectric layer in Eq. 9 [4].

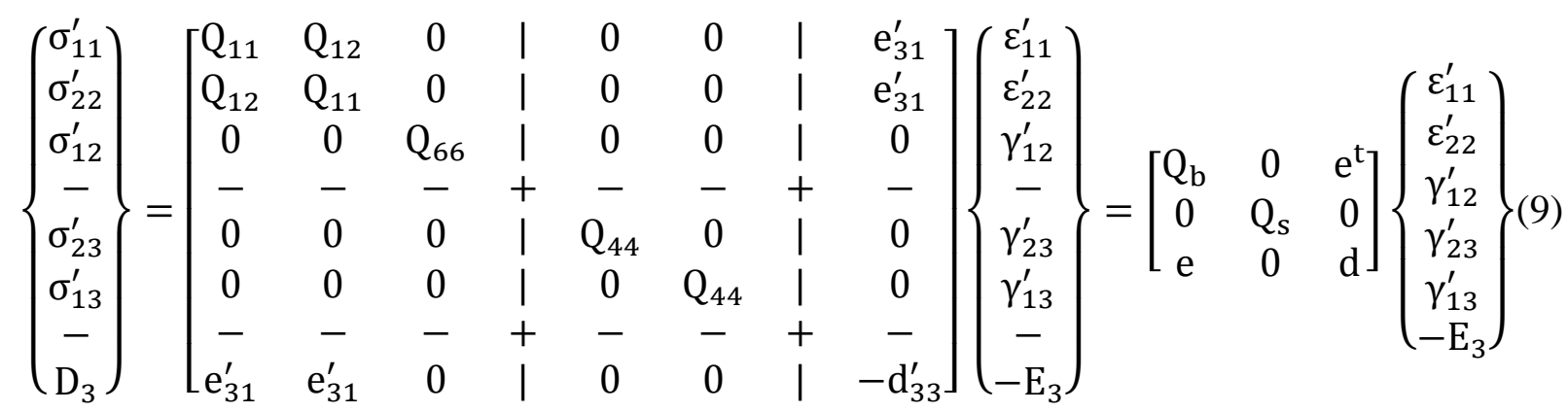

Where we have the effective properties given by Eqs. 10 and 11 .

$$
\begin{aligned}
& Q_{11}=C_{11}^{E}-\frac{C_{13}^{E}{ }^{2}}{C_{33}^{E}}, Q_{12}=C_{12}^{E}-\frac{C_{13}^{E}{ }^{2}}{C_{33}^{E}}, Q_{44}=C_{44}^{E}+\frac{e_{15}^{2}}{d_{11}^{E}}, Q_{66}=2\left(C_{11}^{E}-C_{12}^{E}\right) \\
& \mathrm{e}_{31}^{\prime}=\mathrm{e}_{31}-\frac{\mathrm{C}_{13}^{\mathrm{E}}}{\mathrm{C}_{33}^{\mathrm{E}}} \mathrm{e}_{33}, \mathrm{~d}_{33}^{\prime}=\mathrm{d}_{33}^{\varepsilon}+\frac{\mathrm{e}_{33}^{2}}{\mathrm{~d}_{11}^{\varepsilon}}
\end{aligned}
$$

Starting from Eq. 9, one can use the Classical Laminated Theory to obtain the final constitutive equations for an active laminate. However, it should be noted that some changes to the theory must be applied: both the in-plane and off-plane matrixes $Q_{b}$ and $Q_{s}$ must be rotated in the angle of the fibers and the kinematic assumptions showed in Eq. 6 must be taken into account.

In particular, when the constitutive equation is integrated over the thickness, the effects of these kinematic assumptions creates more compatible generalized efforts over the laminate than the common used normal forces $(\mathrm{N})$ and bending moments $(\mathrm{B})$ : the shear forces (Q) and torcional moments (T).

$$
\begin{aligned}
& \left\{\begin{array}{l}
\mathrm{Q}_{\mathrm{x}} \\
\mathrm{Q}_{\mathrm{y}}
\end{array}\right\}=\sum_{\mathrm{k}=1}^{\mathrm{N}} \int_{\mathrm{x}_{3 \mathrm{k}-1}^{\prime}}^{\mathrm{x}_{3 \mathrm{k}}^{\prime}}\left\{\begin{array}{c}
\sigma_{23}^{\prime} \\
\sigma_{13}^{\prime}
\end{array}\right\} \mathrm{zdz} \\
& \left\{\begin{array}{l}
\mathrm{T}_{\mathrm{x}} \\
\mathrm{T}_{\mathrm{y}}
\end{array}\right\}=\sum_{\mathrm{k}=1}^{\mathrm{N}} \mathrm{x}_{3}^{\prime} \int_{\mathrm{x}_{3 \mathrm{k}-1}^{\prime}}^{\mathrm{x}_{3 \mathrm{k}}^{\prime}}\left\{\begin{array}{c}
\sigma_{23}^{\prime} \\
\sigma_{13}^{\prime}
\end{array}\right\} \mathrm{dz}
\end{aligned}
$$

As such, for simplicity reasons with the element calculations, the classic ABBD laminate constitutive matrix can be extended into the one shown in Eq. 14.

$$
\left\{\begin{array}{c}
\mathrm{N} \\
\mathrm{M} \\
\mathrm{Q} \\
\mathrm{T}
\end{array}\right\}=\left[\begin{array}{cccc}
\mathrm{A} & \mathrm{B} & 0 & 0 \\
\mathrm{~B} & \mathrm{D} & 0 & 0 \\
0 & 0 & \mathrm{G} & \mathrm{G}_{\mathrm{h}} \\
0 & 0 & \mathrm{G}_{\mathrm{h}} & \mathrm{H}
\end{array}\right]\left\{\begin{array}{c}
\varepsilon_{0}^{\prime} \\
\kappa_{\mathrm{f}}^{\prime} \\
\gamma_{0}^{\prime}+\gamma_{1}^{\prime} \\
\kappa_{\mathrm{t}}^{\prime}
\end{array}\right\}
$$

Where: 


$$
\begin{aligned}
& \mathrm{A}_{\mathrm{ij}}=\sum_{\mathrm{k}=1}^{\mathrm{N}} \overline{\left(\mathrm{Q}_{\mathrm{j}}^{\mathrm{k}}\right)_{\mathrm{b}}}\left(\mathrm{x}_{3_{\mathrm{k}}}^{\prime}-\mathrm{x}_{3 \mathrm{k}-1}^{\prime}\right), \mathrm{B}_{\mathrm{ij}}=\frac{1}{2} \sum_{\mathrm{k}=1}^{\mathrm{N}} \overline{\left(\mathrm{Q}_{1 \mathrm{j}}^{\mathrm{k}}\right)_{\mathrm{b}}}\left(\mathrm{x}_{3_{\mathrm{k}}}^{2}-\mathrm{x}_{3_{\mathrm{k}-1}}^{2}\right), \mathrm{D}_{\mathrm{ij}}= \\
& \frac{1}{3} \sum_{\mathrm{k}=1}^{\mathrm{N}} \overline{\left(\mathrm{Q}_{\mathrm{lj}}^{\mathrm{k}}\right)_{\mathrm{b}}}\left(\mathrm{x}_{3_{\mathrm{k}}^{\prime}}^{3}-\mathrm{x}_{3_{\mathrm{k}-1}}^{3}\right)
\end{aligned}
$$

$$
\begin{aligned}
& \mathrm{G}_{\mathrm{ij}}=\sum_{\mathrm{k}=1}^{\mathrm{N}} \overline{\left(\mathrm{Q}_{\mathrm{lj}}^{\mathrm{k}}\right)}\left(\mathrm{x}_{3_{\mathrm{k}}}^{\prime}-\mathrm{x}_{3_{\mathrm{k}-1}}^{\prime}\right), \mathrm{G}_{\mathrm{H}_{\mathrm{ij}}}=\frac{1}{2} \sum_{\mathrm{k}=1}^{\mathrm{N}} \overline{\left(\mathrm{Q}_{\mathrm{lj}}^{\mathrm{k}}\right)_{\mathrm{s}}}\left(\mathrm{x}_{3_{\mathrm{k}}}^{\prime 2}-\mathrm{x}_{3_{\mathrm{k}-1}}^{\prime 2}\right), \mathrm{H}_{\mathrm{ij}}= \\
& \frac{1}{3} \sum_{\mathrm{k}=1}^{\mathrm{N}} \overline{\left(\mathrm{Q}_{\mathrm{lj}}^{\mathrm{k}}\right)_{\mathrm{s}}}\left(\mathrm{x}_{3 \mathrm{k}}^{\prime 3}-\mathrm{x}_{3 \mathrm{k}-1}^{\prime 3}\right)
\end{aligned}
$$

As the uniaxial transversal polarization over the piezoelectric layers $\left(E_{1}=E_{2}=0\right)$ hypothesis was used, there's no need for coordinate transformation of the electrical-coupling and dieletrical matrixes from layer to layer. This fact is enforced by the fact that in general, electrodes as installed in the utmost layers of a laminate, the plates, making the electrical fields always normal to each layer. This way, the integration of the dielectric and piezoelectric coupling parts of the constitutive matrix can be simplified to just a sum of the properties of each layer powdered by said layer thickness:

$$
\begin{aligned}
& \mathrm{e}_{31_{\text {laminate }}^{\prime}}^{\prime}=\sum_{\mathrm{k}=1}^{\mathrm{N}} \mathrm{e}_{31_{\mathrm{k}}}^{\prime}\left(\mathrm{x}_{3_{\mathrm{k}}}^{\prime}-\mathrm{x}_{3_{\mathrm{k}-1}}^{\prime}\right) \\
& \mathrm{d}_{33_{\text {laminate }}}^{\prime}=\sum_{\mathrm{k}=1}^{\mathrm{N}} \mathrm{d}_{33_{\mathrm{k}}}^{\prime}\left(\mathrm{x}_{3 \mathrm{k}}^{\prime}-\mathrm{x}_{3 \mathrm{k}-1}^{\prime}\right)
\end{aligned}
$$

\subsection{Electrical assumptions}

As the electrodes of the laminates are usually installed such as the piezoelectric material is polarized in the thickness direction $\left(x_{3}^{\prime}\right)$, there is no free charge through the laminate thickness. Using this assumption with Gauss' Law, we can write $D_{3}$ as a function of the strains and electric fields:

$$
\begin{gathered}
\mathrm{D}_{3}=\mathrm{e}_{31}^{\prime}\left(\varepsilon_{11}+\varepsilon_{22}\right)+\mathrm{d}_{33}^{\prime} \mathrm{E}_{3} \\
\frac{\partial \mathrm{D}_{3}}{\partial \mathrm{x}_{3}^{\prime}}=\mathrm{e}_{31}^{\prime}\left(\frac{\partial \varepsilon_{11}}{\partial \mathrm{x}_{3}^{\prime}}+\frac{\partial \varepsilon_{22}}{\partial \mathrm{x}_{3}^{\prime}}\right)+\mathrm{d}_{33}^{\prime} \frac{\partial \mathrm{E}_{3}}{\partial \mathrm{x}_{3}^{\prime}}=0
\end{gathered}
$$

Using Eq. 9 with Faraday's Law of induction $E_{3}=-\partial \varphi / \partial x_{3}^{\prime}$, with the piezoelectric boundary conditions $\varphi\left(x_{1}^{\prime}, x_{2}^{\prime}, x_{3}^{\prime}=h / 2\right)=\Delta \varphi, \varphi\left(x_{1}^{\prime}, x_{2}^{\prime}, x_{3}^{\prime}=-h / 2\right)=0$, we obtain the electrical field-difference of potential relation:

$$
\mathrm{E}_{3}=-\mathrm{x}_{3}^{\prime} \frac{\mathrm{e}_{31}^{\prime}}{\mathrm{d}_{33}^{\prime}}\left(\frac{\partial \varepsilon_{11}}{\partial \mathrm{x}_{3}^{\prime}}+\frac{\partial \varepsilon_{22}}{\partial \mathrm{x}_{3}^{\prime}}\right)-\frac{\Delta \varphi}{\mathrm{h}}
$$

Therefore, the electrical field can be obtained from the difference of potential over the electrodes and the plate membrane strains gradient. This mechanical-electrical coupling in the electric fields is explained by the thickness reduction created by the Poisson effect [11]. However, as the term $\left(\partial \varepsilon_{11} / \partial x_{3}^{\prime}+\partial \varepsilon_{22} / \partial x_{3}^{\prime}\right)$ is usually difficult and computational expansive to 
be calculated. Also, this term is only relevant when compared to the difference of potential term in the specific application of the piezoelectric layer being used as a sensor in plates where its thickness is the greatest portion of the whole laminate - over $60 \%$ of the laminate total thickness according to the literature [11]. Subsequently, this term can be ignored, and a discretized relation between the electric field and the difference of potential can be written.

$$
\mathrm{E}_{3}=\mathrm{B}_{\varphi} \varphi=-\frac{1}{\mathrm{~h}_{\mathrm{i}}} \varphi_{\mathrm{i}}
$$

Where $\varphi_{i}$ and $h_{i}$ are, respectively, the difference of potential and the thickness over each node of the element.

\section{FINITE ELEMENT EQUATIONS AND IMPLEMENTATION AS A UEL SUB- ROUTINE}

In this section the final equations for the finite element are obtained, the matrixes and system of equation is presented and some assumptions about the drilling degree of freedom and the piezoelectric boundary conditions are discussed.

Given the energy potential over a single element:

$$
\Pi=\mathrm{U}_{\mathrm{e}}+\mathrm{K}+\mathrm{P}+\mathrm{Q}
$$

Where $U_{e}$ is the total energy deformation, $\mathrm{K}$ is the kinematic energy, $\mathrm{Q}$ is the work of dissipative internal forces, and $\mathrm{P}$ is the work from the external loads, by the Principle of stationarity of the potential energy, the system will be in balance when:

$$
\delta \Pi=\delta \mathrm{U}_{\mathrm{e}}+\delta \mathrm{K}+\delta \mathrm{P}+\delta \mathrm{Q}=0
$$

The $\delta U_{e}$ portion is given by the integration of the specific electric-mechanic enthalpy (or piezoelectric Gibbs' energy) over the element volume; $\delta$ h can be given in the e-form by [4]:

$$
\delta \mathrm{h}=\frac{1}{2}(\delta \varepsilon \cdot \sigma-\delta \mathrm{E} \cdot \mathrm{D})
$$

Using Eq. 24 with the constitutive relations in Eq. 9, and applying the classical relations for finite element for the calculation of the $\delta K$ and $\delta P$ portions, found in literature [2] and assuming $\delta Q$ can be modeled as a linear viscous damping (with the damping matrix $C$ ), it is obtained the elemental equilibrium equation: 


$$
\begin{aligned}
\frac{1}{2} \int_{V} \rho \delta \mathrm{u} \cdot \ddot{\mathrm{u}}+ & \mathrm{C} \delta \mathrm{u} \cdot \dot{\mathrm{u}}+\delta \varepsilon^{\prime}: \mathrm{C}^{\mathrm{E}} \varepsilon^{\prime}-\delta \varepsilon^{\prime}: \mathrm{e}^{\mathrm{t}} \mathrm{E}-\delta \mathrm{E}: \mathrm{e} \varepsilon^{\prime}-\delta \mathrm{E}: \mathrm{d}^{\varepsilon} \mathrm{E} \mathrm{dV} \\
& =\int_{V} \delta \mathrm{u} \cdot \mathrm{bdV}+\int_{\mathrm{S}} \delta \mathrm{u} \cdot \mathrm{td} S+\delta \mathrm{u} \cdot \mathrm{F}-\int_{\mathrm{S}} \delta \varphi \cdot \mathrm{qd} S-\varphi \cdot \mathrm{Q}
\end{aligned}
$$

Where $u=\left\{u_{1}, u_{2}, u_{3}, \theta_{1}, \theta_{2}, \theta_{3}\right\}^{n^{T}}$,for $\mathrm{n}=$ number of nodes in the element is a vector containing each mechanical degree of freedom presented in the element, $\varphi=\left\{\varphi^{n}\right\}^{T}$, for $\mathrm{n}=$ number of nodes in the element is a vector containing the difference of potential in each node; $\rho$ is the density of the plate; b, t, q, F, and Q are, respectively, the body forces, surface forces, electrical charges distribution over the surface of an electrode, concentrated forces and electrical charges.

As the element has five degrees of freedom in the local system, but after coordinates transformations, recovers six degrees of freedom, the last rotation $\theta_{3}$ is a virtual dof with no stiffness that creates a trivial solution for system of equation $\left(\overline{0} \theta_{3}^{n}=\overline{0}\right)$. Because of the coordinate transformations, unless the element local system is aligned with the global system this null solution is hidden. This is called a drilling degree of freedom. To solve this problem, a virtual transversal shear energy $\bar{S}$, found in Eq. 27, must be added to the problem where $\alpha^{i}$ is a scalar to be set as small as possible such as the extra stiffness makes the system solvable. To account for this extra energy, the $B_{u}$ matrix must be include a new $B_{t}$ matrix that calculates the contribution of this new term. A more detailed explanation of this problem can be found in literature.

$$
\begin{gathered}
\overline{\mathrm{S}}=\frac{1}{2} \alpha^{\mathrm{i}} \mathrm{Gh} \int_{\mathrm{A}} \theta_{3}^{\prime}-\frac{1}{2}\left(\frac{\partial \mathrm{u}_{2}^{\prime}}{\partial \mathrm{x}_{1}^{\prime}}-\frac{\partial \mathrm{u}_{1}^{\prime}}{\partial \mathrm{x}_{2}^{\prime}}\right) \mathrm{dA} \\
\mathrm{B}_{\mathrm{u}}=\left[\begin{array}{cc}
\mathrm{B}_{\mathrm{m}} & 0 \\
0 & \mathrm{~B}_{\mathrm{f}} \\
\mathrm{B}_{\mathrm{s}_{0}} & \mathrm{~B}_{\mathrm{s}_{1}}^{\mathrm{n}} \\
0 & \mathrm{~B}_{\mathrm{s}_{\mathrm{f}}}
\end{array}\right]^{\mathrm{n}}+\mathrm{B}_{\mathrm{t}}
\end{gathered}
$$

By solving Eq. 26 for every compatible virtual displacement $\delta u$ and $\delta \varphi$ a final system of equations can be written.

$$
\begin{aligned}
M \ddot{u}+C \dot{u}+K_{u u} u+K_{u \varphi} \varphi & =F \\
K_{\varphi u} u+K_{\varphi \varphi} \varphi & =Q
\end{aligned}
$$

Where, using the Gauss Quadrature integration method the matrixes $M, C, K_{u u}, K_{u \varphi}, K_{\varphi u}$ and $K_{\varphi \varphi}$ are given by:

$$
\begin{gathered}
M=\sum_{i, j=1}^{8} \frac{\rho_{i} h_{i}}{2} H_{u}^{T} H_{u} \operatorname{det}\left({\frac{\partial x^{-1}}{\partial \zeta}}^{-1}\right) w_{i} \\
C=a M+b K_{u u}(31)
\end{gathered}
$$




$$
\begin{aligned}
& \mathrm{K}_{\mathrm{uu}}=\sum_{\mathrm{i}, \mathrm{j}=1}^{8} \mathrm{w}_{\mathrm{i}} \operatorname{det}\left(\frac{\partial \mathrm{x}^{-1}}{\partial \zeta}\right)\left(\mathrm{B}_{\mathrm{u}}^{\mathrm{T}}\left[\begin{array}{cccc}
\mathrm{A} & \mathrm{B} & 0 & 0 \\
\mathrm{~B} & \mathrm{D} & 0 & 0 \\
0 & 0 & \mathrm{G} & \mathrm{G}_{\mathrm{H}} \\
0 & 0 & \mathrm{G}_{\mathrm{H}} & \mathrm{H}
\end{array}\right] \mathrm{B}_{\mathrm{u}}\right) \\
& \mathrm{K}_{\mathrm{u} \varphi}=\sum_{\mathrm{i}, \mathrm{j}=1}^{8} \mathrm{w}_{\mathrm{i}} \operatorname{det}\left({\frac{\partial \mathrm{x}^{-1}}{\partial \zeta}}^{-1}\right)\left(\mathrm{B}_{\mathrm{u} \varphi}^{\mathrm{T}} \mathrm{e}^{\mathrm{T}} \mathrm{B}_{\varphi}\right) \\
& \mathrm{K}_{\mathrm{u} \varphi}=\sum_{\mathrm{i}, \mathrm{j}=1}^{8} \mathrm{w}_{\mathrm{i}} \operatorname{det}\left({\frac{\partial \mathrm{x}^{-1}}{\partial \zeta}}^{-1}\right)\left(\mathrm{B}_{\varphi}^{\mathrm{T}} \mathrm{eB}_{\mathrm{u} \varphi}\right) \\
& \mathrm{K}_{\varphi \varphi}=\sum_{\mathrm{i}, \mathrm{j}=1}^{8} \mathrm{w}_{\mathrm{i}} \operatorname{det}\left({\frac{\partial \mathrm{x}^{-1}}{\partial \zeta}}^{-1}\right)\left(\mathrm{B}_{\varphi}^{\mathrm{T}} \mathrm{d}^{\varepsilon} \mathrm{B}_{\varphi}\right) \\
& F_{i}=\int_{V} \phi_{k} b_{i}^{k} d V+\int_{S} \phi_{k} t_{i}^{k} d S+\phi_{k} F_{i}^{k}, Q_{i}=-\int_{S} \frac{1}{h_{i}} q^{i} d S-\varphi \cdot Q_{i}
\end{aligned}
$$

Where $w_{i}$ are the Gauss Quadrature weights and $a$ and $b$ are the Rayleight damping parameters.

One final note about the system of equations must be made. As the electrodes over piezoelectric layers are continuous, there is an electrical boundary condition that thorough the same electrode there is an equipotential voltage. To account for that in this model, after the global matrixes are created from the elemental matrixes, the piezoelectric and dielectric matrixes $K_{u \varphi}, K_{\varphi u}$ and $K_{\varphi \varphi}$, as well as the $Q$ vector must be reduced in dimension so that only one potential degree of freedom $\varphi$ remains for each distinct electrode in the model. There are several methods for this, but in this model the one proposed by literature [3] is chosen in which a reduced matrix is generated with a number of items - lines for $K_{p u}$, columns for $K_{u p}$ and terms for $K_{\varphi \varphi}$ - equal to the number of electrodes in the system is created as the sum for the position in the former matrix for every degree of freedom in the same electrode.

\section{STUDY CASE AND RESULTS}

This section presents a study case to test, validate and evaluate the limitations of the finite element proposed in the present work using experimental data found in reference [7]. The experiments consisted in the modal analysis of a clamped-free aluminum beam of dimensions as follow: $530 \times 50.85 \times 3.3 \mathrm{~mm}$. Initially, the experiments were made with a clean beam using PCB Piezoeletronics 333B30 SN 3228 accelerometers; in a second stage Midè QP10-n piezoelectric patches were attached to one of its faces in the positions shown in Fig. 2. One of the piezoelectric patches was used as a sensor and the other as an actuator. 


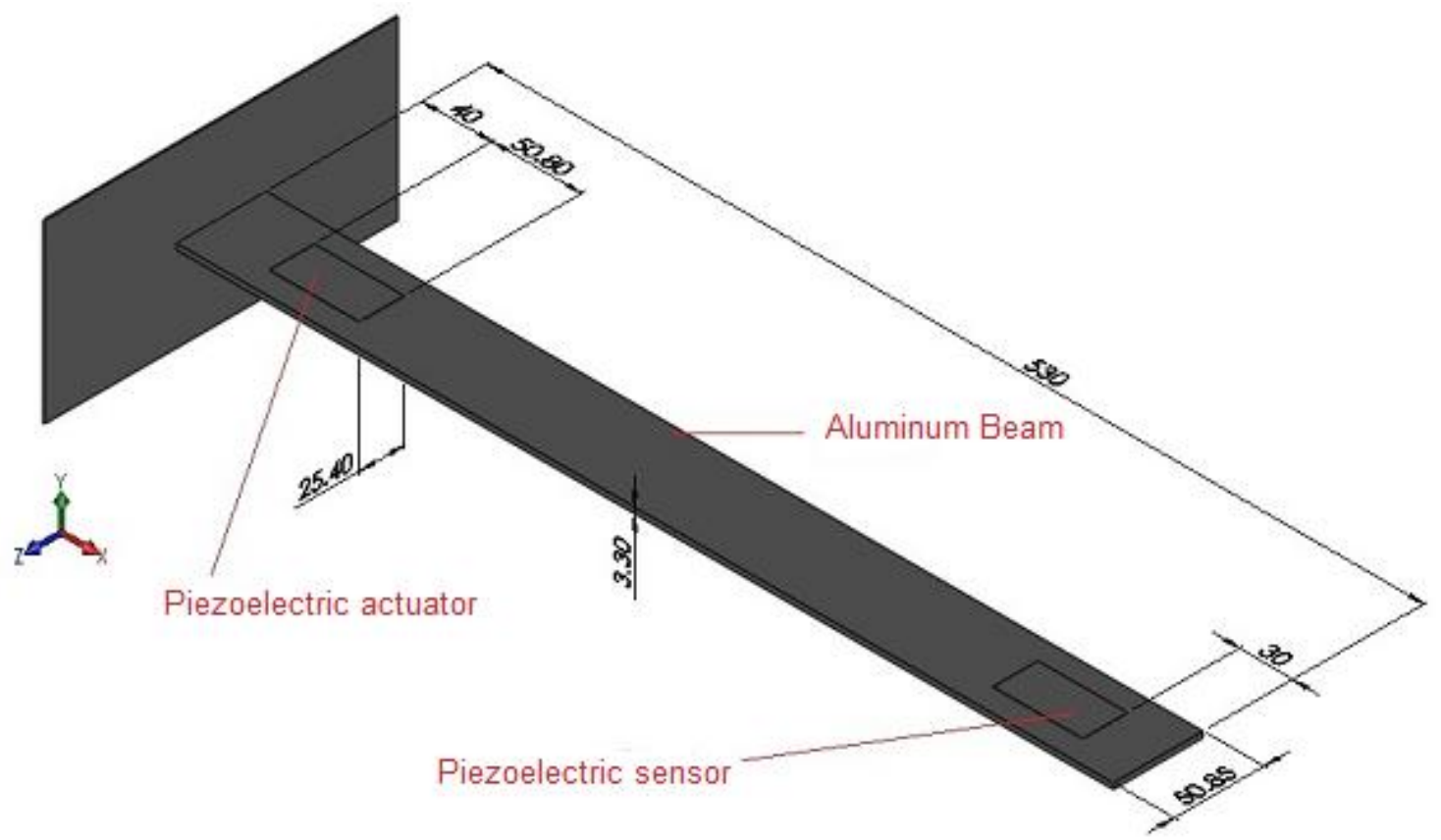

Figure 2. Dimensions of the beam used in the experiment

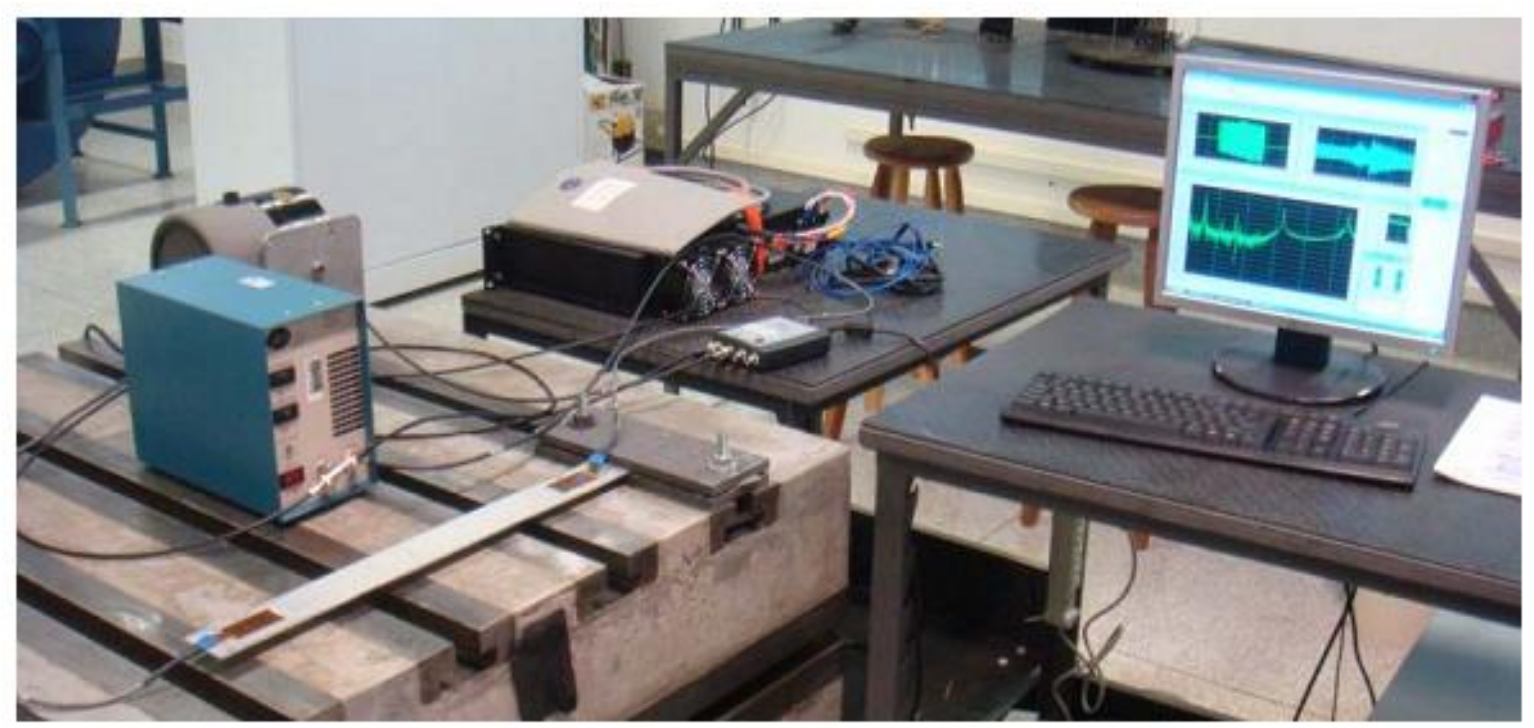

Figure 3. Experiment and equipment used

Initially, as a control parameter to guarantee that the electric coupled parts of the model were not concealing the ability of the model to correctly simulate a pure mechanic system; the undamped clamped-free experimental modal analysis of the beam, without piezoelectric layers, was simulated using both the present model, implemented in a Python routine and the commercial finite element package Abaqus v6.10, with models constructed with shell elements (S8R) and solid elements (C3D20). The properties used for the aluminum beam in this and all subsequent analysis are found in Table 1. The meshes used for the shell - both implemented and from Abaqus - and solid elements are found in Fig. 3. The natural frequencies and frequency responses functions obtained were compared with experimental results and are 
found in Table 2 and Fig. 5.

Table 1. Properties for the aluminum beam used in the simulations

\begin{tabular}{ll}
\hline Property & Value \\
\hline $\mathrm{E}[\mathrm{GPa}]$ & 69.00 \\
$\mathrm{~N}$ & 0.33 \\
$\rho\left[\mathrm{kg} / \mathrm{m}^{3}\right]$ & 2697 \\
\hline
\end{tabular}

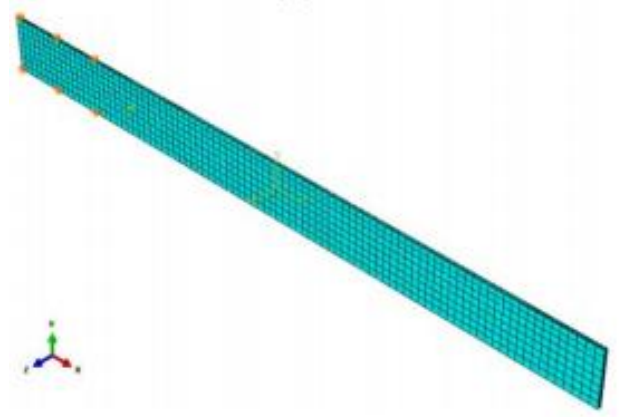

(a)

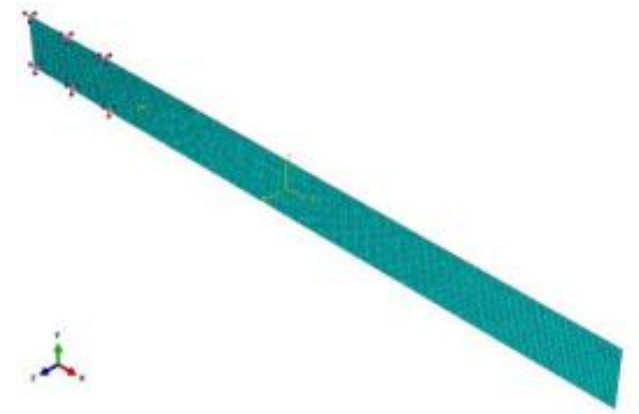

(b)

Figure 4. Meshes used for the solid (a) and shell models (b)

It can be seen from both Table 2 and Figure 4 that the present element performed with the same level of accuracy as the commercial elements. Both got a relative error to the experimental result between $1 \%$ and 3,5\%. Also, neither of the shell elements nor the experiment were able to obtain the third vibration mode, a bending over the xy plane. For the numerical solutions, that can be explained due to premise of not including the transversal normal strain $\varepsilon_{33}$ in the models and poorer prediction of transversal stresses comparing to the solid elements. For the experiment this happened because the configuration of the accelerometers and piezoelectric patches as in the configuration used the degrees of freedom in the xy plane needed to capture this mode were not being sensed.

Table 2. Natural frequencies and relative errors between simulations and experimental results for the clamped-free pure aluminum beam

\begin{tabular}{lllllll}
\hline $\begin{array}{l}\text { Natural Frequen- } \\
\text { cy }\end{array}$ & $\omega_{1}[\mathrm{~Hz}]$ & $\omega_{2}[\mathrm{~Hz}]$ & $\omega_{3}[\mathrm{~Hz}]$ & $\omega_{4}[\mathrm{~Hz}]$ & $\omega_{5}[\mathrm{~Hz}]$ & $\omega_{6}[\mathrm{~Hz}]$ \\
\hline Mode Type & Bending & Bending & $\begin{array}{l}\text { Bending on the XY } \\
\text { plane }\end{array}$ & Bending & Torsion & Bending \\
\hline Experimental & 9.687 & 57.968 & - & 159.687 & 188.125 & 318.281 \\
Abaqus Solid & 9.983 & 59.267 & 143.42 & 165.330 & 193.386 & 324.649 \\
Relative error & $3.05 \%$ & $2.22 \%$ & - & $3.35 \%$ & $2.79 \%$ & $2.00 \%$ \\
Abaqus Shell & 9.846 & 58.934 & - & 164.328 & 192.384 & 323.647 \\
Relative error & $164 \%$ & $1.66 \%$ & - & $2.29 \%$ & $2.22 \%$ & $1.68 \%$ \\
Present Element & 9.505 & 59.576 & - & 167.040 & 192.927 & 328.311 \\
Relative error & $1.87 \%$ & $2.77 \%$ & - & $4.60 \%$ & $2.55 \%$ & $3.15 \%$ \\
\hline
\end{tabular}




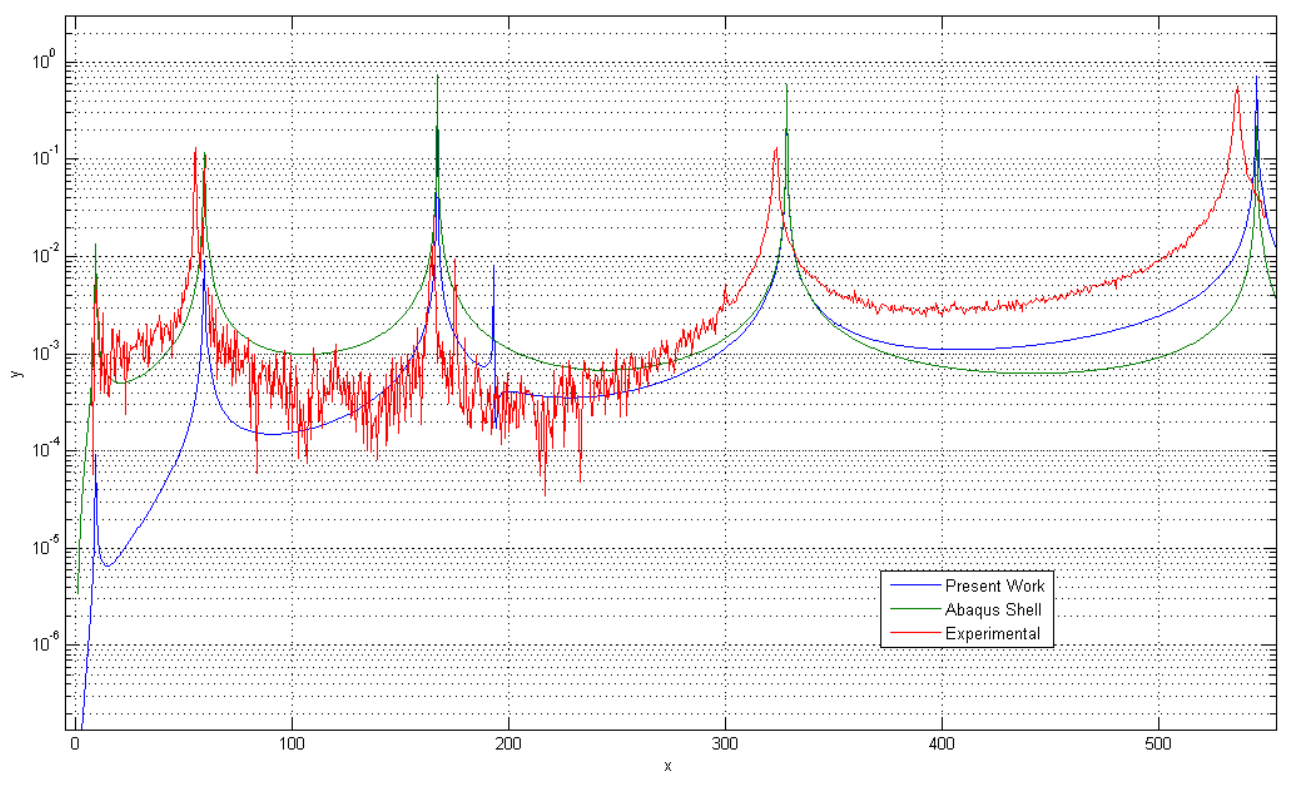

Figure 5. Frequency response function measured experimentally and simulated for the aluminum beam

The same study was done using the data from the aluminum beam with the attached piezoelectric patches. The properties for the piezoelectric patches are found in Table 3 and were obtained by numerically obtained by Medeiros using a representative volume element methodology [8]. The solution was not compared to Abaqus' shell element as the package doesn't have shell element with piezoelectric capacities, and the boundary conditions of joining solid elements to shell elements were considered toxic to the comparison. The meshes used are displayed at Fig. 6 . It must be noted that a mesh convergence test were done for both models, and these are the sparser mesh considered numerically satisfactory. This information is important when analyzing the processing time of both models.

Table 1. Properties for the piezoelectric patches used in the simulations

\begin{tabular}{ll}
\hline Property & Value \\
\hline $\mathrm{C}_{11}[\mathrm{GPa}]$ & 53.2711 \\
$\mathrm{C}_{12}[\mathrm{GPa}]$ & 4.8380 \\
$\mathrm{C}_{13}[\mathrm{GPa}]$ & 16.9226 \\
$\mathrm{C}_{33}[\mathrm{GPa}]$ & 38.6050 \\
$\mathrm{C}_{44}[\mathrm{GPa}]$ & 1.8418 \\
$\mathrm{C}_{66}[\mathrm{GPa}]$ & 1.8170 \\
$\mathrm{e}_{13}\left[\mathrm{C} / \mathrm{m}^{2}\right]$ & -4.3248 \\
$\mathrm{e}_{15}\left[\mathrm{C} / \mathrm{m}^{2}\right]$ & 0.2599 \\
$\mathrm{e}_{33}\left[\mathrm{C} / \mathrm{m}^{2}\right]$ & 10.7469 \\
$\mathrm{~d}_{11}[\mathrm{nF} / \mathrm{m}]$ & 7.7362 \\
$\mathrm{~d}_{33}[\mathrm{nF} / \mathrm{m}]$ & 5.5257 \\
$\rho\left[\mathrm{kg} / \mathrm{m}^{3}\right]$ & 7400 \\
\hline
\end{tabular}




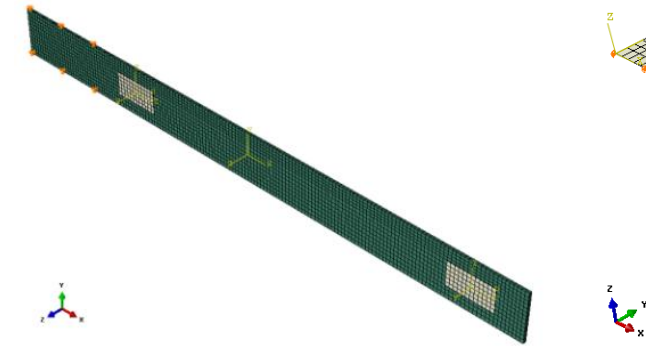

(b)

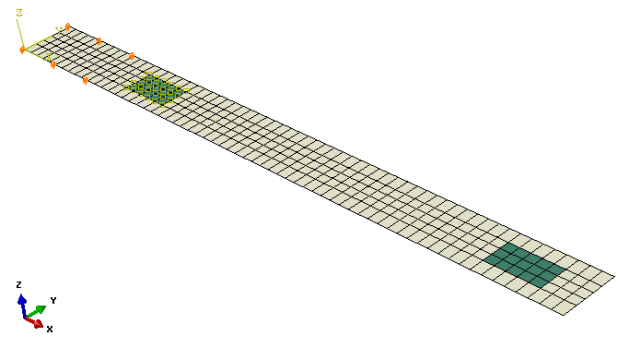

(b)

Figure 6. Meshes used for the solid (a) and shell models (b) including the piezoelectric patches and the electrodes

Table 4. Natural frequencies and relative errors between simulations and experimental results for the clamped-free aluminum beam with piezoelectric patches

\begin{tabular}{lllllll}
\hline $\begin{array}{l}\text { Natural Fre- } \\
\text { quency }\end{array}$ & $\omega_{1}[\mathrm{~Hz}]$ & $\omega_{2}[\mathrm{~Hz}]$ & $\omega_{3}[\mathrm{~Hz}]$ & $\omega_{4}[\mathrm{~Hz}]$ & $\omega_{5}[\mathrm{~Hz}]$ & $\omega_{6}[\mathrm{~Hz}]$ \\
\hline Mode Type & Bending & Bending & $\begin{array}{l}\text { Bending on } \\
\text { the XY plane }\end{array}$ & Bending & $\begin{array}{l}\text { Torsion } \\
\text { (Antiressonant) }\end{array}$ & Bending \\
\hline Experimental & 9.375 & 58.750 & - & 164.375 & 186.875 & 322.50 \\
Abaqus Solid & 9.9018 & 59.118 & - & 164.328 & - & 321.643 \\
Relative error & $5,619 \%$ & $0,0626 \%$ & - & $0,0003 \%$ & - & $0,027 \%$ \\
Present Ele- & 9.321 & 59.161 & - & 165.40 & - & 325.10 \\
ment & $0,057 \%$ & $0,070 \%$ & - & $0,00624 \%$ & - & $0,0806 \%$ \\
Relative error & 0,050 & & & \\
\hline
\end{tabular}

The natural frequencies and frequency response functions for both, found in Table 5, models were accurately calculated, with the fifth mode not being captured by either models, as the presence of the piezoelectric patches apparently suppressed this mode, resulting in a anti-resonance in the experimental results.

In addition to the natural frequencies and frequency response functions, the processing time between Abaqus' models and the implemented model must be compared. For both models, using the sparser mesh found that still converged in relation to mesh size, the implemented routine containing the presented element took 32 '23" to finish solving the problem; Abaqus' model took 3h8'17'. This large difference in time processing is caused by the number of elements, as solid elements require a finer mesh to capture the results accurately comparing to shell elements.

Analyzing the frequency response the implemented model introduced several antiresonances in the system not captured by the experiment. The authors are unsure what the cause of this phenomenon may be, and will be better studied in future works. 


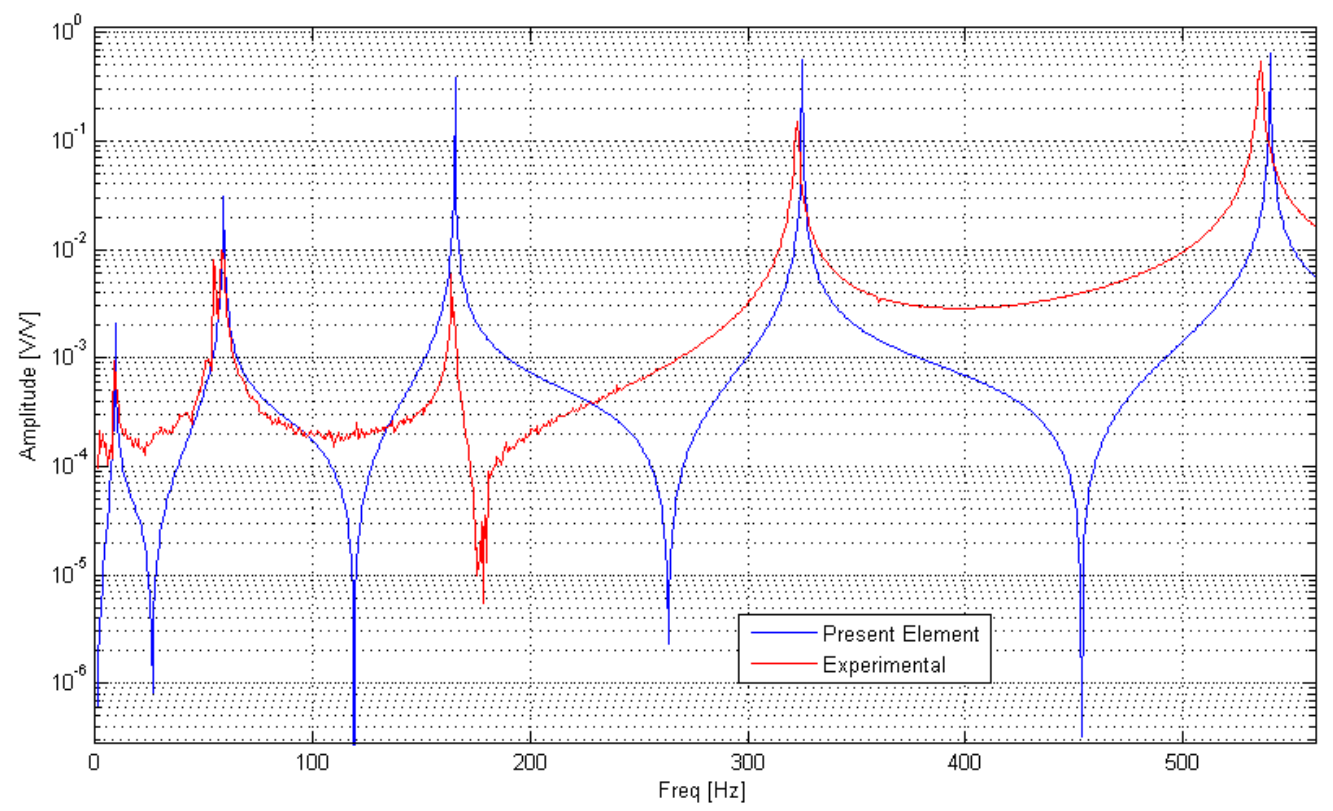

Figure 7. Frequency response function measured experimentally and simulated for the aluminum beam with the piezoelectric patches

\section{CONCLUSIONS}

In this paper, a bi-dimensional quadratic shell finite element, with eight nodes, for curved superficies was proposed based upon different works found in the literature and by adapting the classic degenerated shell element presented by literature [13] into a smart composite laminated shell element by including the electro-mechanic coupling, the piezoelectric effects and the composite materials constitutive equations. The basic assumptions used were the Reissner-Mindlin thick plate hypothesis for the mechanical behavior and the transversal polarized piezoelectric layers with equipotential voltage electrodes.

The model was implemented in a Python subroutine, and numerical results from modal analysis of an aluminum beam with and without piezoelectric patches were compared to experimental data and simulations made using the commercial finite element package Abaqus. Both results containing and not containing the piezoelectric patches were satisfactory, with largest relative error between the model and experiments being less than 5\%. The implemented element also had an accuracy of the same level as the commercial elements. However, due to the commercial package chosen not having shell elements with piezoelectric capacity and electrical degrees of freedom, the efficiency of the implemented model was much greater, solving the problem in $16 \%$ off the time Abaqus' model took.

Some discrepancies between the shape of the frequency response functions found in the experiments and the implemented routine were found, especially some anti-resonances that appeared in the test with piezoelectric patches. The authors are unsure about the causes of such occurrences, and a deeper study of the fact will be made in future works. 


\section{ACKNOWLEDGEMENTS}

The authors would like to thank Research Foundation of State of Sao Paulo FAPESP (process numbers: 09/00544-5 and 10/13596-0), as well as, CNPq and FAPEMIG for partially funding the present research work through the INCT-EIE, as well as to thank Prof. Reginaldo Teixeira Coelho from EESC-USP (Escola de Engenharia de São Carlos - Universidade de São Paulo) for kindly lending the licenses for the Abaqus software.

\section{REFERENCES}

[1] Ahmad S., Irons B. M., Zienkiewicz O. C., "Analysis of thick and thin shell structures by curved finite elements". Int. J. Numer. Methods Eng., 2, 419-451, 1970.

[2] Bathe, K., "Finite Element Procedures", Prentice Hall, 1996.

[3] De Marqui Jr., C. J.; Erturk, A.; Inman, D. J.; "An electromechanical finite element model for piezoelectric energy harvester plates”, Journal of Sound and Vibration, 327, 2009.

[4] Ikeda, T., "Fundamentals of Piezoelectricity", Oxford UniversityPress Inc., 1996.

[5] Marinkovic, D., Köppe H., and Gabbert, U, "Numerically Efficient Finite Ele-ment Formulation for Modeling Active Composite Laminates". Mechanics of Advanced Materials and Structures, 13, 379-392, 2006.

[6] Marinkovic, D., Köppe H., Gabbert, U, "Accurate Modeling of the Electric Field within Piezoelectric Layers for Active Composite Structures". Journal for Intelligent Material Systems and Structures, 18, 503-514, 2007.

[7] Medeiros, R., "Desenvolvimento de uma Metodologia Computacional para Determinar Coeficientes Efetivos de Compósitos Inteligentes", (Masters Thesis), Escola de Engenharia de São Carlos, Universidade de São Paulo, 2012.

[8] Medeiros, R.; Moreno, M. E.; Tita, V., "Electromechanical response of 1-5 pie-zoeletric fiber composites: a unit cell approach for numerical evaluation of effective properties.", In: VI National Congress of Mechanical Engineering - CONEM 2010, 2010.

[9] Ochoa, O.O. and Reddy, "Finite Element Analysis of Composite Laminates", Kluwer Academic Publishers, Dordrecht, Boston, London.

[10] Paik, S. H.; Yoon, T. H.; Shin, S. J.; Kim, S. J, "Computational material characterization of active fiber composite". Journal of Intelligent Material Systems and Structures, 18, 19-28, 2007. 
[11] Piefort, V, "Finite element modelling of piezoelectric active structures". (PhD. Thesis) Faculty of Applied Sciences, Université Libre de Bruxelles, 2009.

[12] Tzou, H.S., "Piezoelectric Shells", Kluwer Academic Publishers, 1993.

[13] Zienkiewicz, O. C., Taylor, R. L. "The Finite Element Method", Butterworth Heinemann, 2000. 